\title{
Biological and Application-Oriented Factors Influencing Plant Disease Suppression by Biological Control: A Meta-Analytical Review
}

\author{
P. S. Ojiambo and H. Scherm
}

Department of Plant Pathology, University of Georgia, Athens 30602.

Current address of P. S. Ojiambo: International Institute of Tropical Agriculture (IITA), Oyo Road, PMB 5320, Ibadan, Nigeria. Accepted for publication 22 June 2006.

\begin{abstract}
Ojiambo, P. S., and Scherm, H. 2006. Biological and application-oriented factors influencing plant disease suppression by biological control: A meta-analytical review. Phytopathology 96:1168-1174.

Studies to evaluate the effectiveness of biological control in suppressing plant disease often report inconsistent results, highlighting the need to identify general factors that influence the success or failure of biological control in plant pathology. We conducted a quantitative synthesis of previously published research by applying meta-analysis to determine the overall effectiveness of biocontrol in relation to biological and application-oriented factors. For each of 149 entries (antagonist-disease combinations) from 53 reports published in Biological \& Cultural Tests between 2000 and 2005, an effect size was calculated as the difference in disease intensity expressed in standard deviation units between the biocontrol treatment and its corresponding untreated control. Effect sizes ranged from -1.15 (i.e., disease strongly enhanced by application of the biocontrol agent) to 4.83 (strong disease suppression by the antagonist) with an overall weighted mean of 0.62 , indicating moderate effectiveness on average. There were no significant $(P>0.05)$ differences in effect sizes between entries from studies carried out in the greenhouse versus the

field, between those involving soilborne versus aerial diseases, or among those carried out in conditions of low, medium, or high disease pressure (expressed relative to the disease intensity in the untreated control). However, effect sizes were greater on annual than on perennial crops, regardless of whether the analysis was carried out for all entries $(P=0.0268)$ or for those involving only soilborne diseases $(P=0.0343)$. Effect sizes were not significantly different for entries utilizing fungal versus bacterial biocontrol agents or for those targeting fungal versus bacterial pathogens. However, entries that used $r$-selected biological control agents (i.e., those having short generation times and producing large numbers of short-lived offspring) were more effective than those that applied antagonists that were not $r$-selected $(P=0.0312)$. Interestingly, effect sizes for entries that used Bacillus spp. as biological control agents were lower than for those that applied other antagonists $(P=0.0046$ for all entries and $P=0.0114$ for soilborne diseases). When only aerial diseases were considered, mean effect size was greater for entries that received one or two sprays than for those that received more than eight sprays of the biocontrol agent $(P=$ 0.0002). This counterintuitive result may indicate that investigators often attempt unsuccessfully to compensate for anticipated poor performance in antagonist-disease combinations by making more applications.
\end{abstract}

Several factors have led to an increased interest in the application of biological control for plant disease management $(10,30$, 37,42 ), including the desire for a more sustainable approach to agriculture in general, concerns about the impact of synthetic agrichemicals on human health and the environment, the high frequency of pathogen populations resistant to commonly used fungicides, the increasing cost of soil fumigation, and the continued search for methyl bromide alternatives. As a result of the increased investment in biological control research and development, numerous biocontrol products have been labeled for commercial use. For example, at least 37 biocontrol agents were available commercially in the United States in 2000 (29). Nonetheless, biological products represent only a minute fraction of the global pesticide market; in fact, the global value of biofungicide sales in 1998 was valued at $<0.2 \%$ of the global market for synthetic fungicides in the same year (33).

The relatively low adoption of biological control in agricultural practice emphasizes the need to critically and quantitatively examine the factors that determine success or failure of biological control for plant disease management. Although biocontrol has been effective in controlling a range of plant diseases, there are various reports in the literature that question its general effective-

Corresponding author: H. Scherm; E-mail address: scherm@uga.edu

DOI: 10.1094/PHYTO-96-1168

(C) 2006 The American Phytopathological Society ness $(9,18,30,35,42)$. Vasudevan et al. (44) observed that this inconsistency in performance has plagued researchers and their efforts to exploit biocontrol agents for commercial use. It generally is acknowledged that disease suppression by biological control is the result of complex interactions among the antagonist, the pathogen, the host plant and its associated microbial community, and the physical environment $(2,17,26,46)$. However, we are unaware of quantitative studies to synthesize data on the relative efficacy of a range of biocontrol agents in suppressing plant disease in relation to biological and application-oriented factors. As such, several fundamental questions regarding the level of disease suppression by biocontrol agents still remain unanswered. For example, is biological control generally more successful for soilborne or for aerial diseases? To what extent is its effectiveness determined by overall disease pressure? Is biocontrol really more effective in the greenhouse than in the field, as is assumed generally (35)? Are there certain factors related to the biology of the pathogen or the biocontrol agent (e.g., fungus versus bacterium, $r$ - versus $K$-selected life history) that help predict success or failure of biological control? And how significant and consistent are these effects across a wide range of antagonistdisease combinations?

Answering the types of questions posed above requires the quantitative synthesis of research results across a large number of studies. This can be accomplished with meta-analysis, a set of statistical techniques developed to integrate and analyze results obtained from independent studies. Meta-analysis utilizes infor- 
mation on "effect size" (i.e., the relative magnitude of the observed effect-disease suppression in this case-weighted by intrinsic error rate) $(15,21,34)$. Here, we present results of a metaanalysis to synthesize previously published research on the use of biological control for plant disease suppression with the objective of understanding the relative efficacy of biocontrol in relation to selected biological and application-oriented factors. Results of a similar analysis that focused on biological control of arthropod pests and weeds have been reported recently (43).

\section{EFFICACY DATABASE}

Data were extracted from reports published in Biological \& Cultural Tests (B\&C Tests) between 2000 (vol. 15) and 2005 (vol. 20) This source was chosen because it publishes a diverse range of disease biocontrol studies irrespective of whether their results are positive (i.e., statistically significant) or negative. In contrast, a tendency toward publishing mostly positive results in more traditional research journals could lead to biased or erroneous conclusions when applying meta-analysis (38). In addition, reports published in B\&C Tests were considered most appropriate for our analysis in that they tend to be application-oriented rather than focusing on laboratory or model systems. As such, the results are likely to be more indicative of biocontrol performance in field conditions given the current state of technology.
The following criteria were applied to determine whether or not a particular report could be included in the analysis. First, the report had to provide at least one measure of disease intensity such as disease incidence, disease severity, area under the disease progress curve, or disease intensity expressed as an index or on an arbitrary scale. In cases where both incidence and severity were available, the latter was used in the analysis. Second, an estimate of the pooled sample standard deviation $s_{\text {pooled }}$ from the analysis of variance had to be provided for the report to be useful. In a number of cases, $s_{\text {pooled }}$ was calculated from Fisher's least significant difference (LSD) values presented in the reports (8). Third, reports that evaluated combinations of multiple biological control agents or of biological agents applied together with cultural practices or chemical products were not included because it would have been impossible to calculate the contribution of each individual antagonist in such cases. Of the 92 disease biocontrol reports published in B\&C Tests between 2000 and 2005, 53 reports ("studies") with 149 "entries" (antagonist-disease combinations) met the criteria outlined above; most of the studies that could not be included lacked statistical information sufficient to calculate $s_{\text {pooled }}$, a common problem in scientific data reporting (15). The 53 studies were conducted in either the greenhouse or the field to evaluate the effectiveness of registered or experimental biocontrol agents in suppressing disease for a range of annual and perennial pathosystems (Table 1).

TABLE 1. Antagonist-pathogen combinations included in a meta-analysis to determine the effect size of disease suppression by biological control based on reports published in Biological \& Cultural Tests between 2000 and 2005

\begin{tabular}{|c|c|c|c|c|}
\hline Biocontrol agent species & $\begin{array}{l}\text { Number } \\
\text { of entries }\end{array}$ & Strain or product name & Target pathogens & Hosts \\
\hline Arthrobacter ilicis & 1 & $3026 \mathrm{C}$ & Gaeumannomyces graminis var. tritici & Wheat \\
\hline Azospirillum brasilense & 1 & Recharge & Fusarium solani & Cotton \\
\hline Azotobacter chrococcum & 1 & Agropro ZX & Erwinia tracheiphila & Cucumber \\
\hline Bacillus amyloliquefaciens & 2 & BioYield, IN937a & Alternaria solani, E. tracheiphila & Cucumber, tomato \\
\hline Bacillus licheniformis & 2 & EcoGuard & Colletotrichum graminicola, Rhizoctonia solani & Bermudagrass \\
\hline Bacillus pumilus & 7 & $\begin{array}{l}\text { SE34, Sonata, Yield } \\
\text { Shield }\end{array}$ & $\begin{array}{l}\text { A. solani, F. solani, Gibberella zeae, Podosphaera } \\
\text { leucotricha, R. solani, Sphaerotheca humuli }\end{array}$ & $\begin{array}{l}\text { Apple, hop, soybean, snap } \\
\text { bean, tomato, wheat }\end{array}$ \\
\hline Bacillus subtilis & 44 & $\begin{array}{l}\text { Companion, GB03, } \\
\text { HiStick, Kodiak, } \\
\text { MBI600, OSU140/1, } \\
\text { QRD713AS, } \\
\text { QRD713/4/5, QST, } \\
\text { Serenade, Subtilex, } \\
\text { TrigoCor }\end{array}$ & $\begin{array}{l}\text { A. solani, Botryosphaeria dothidea, } \\
\text { Fusicladosporium carpophilum, Colletotrichum } \\
\text { gloeosporioides, Erwinia amylovora, Fusarium } \\
\text { oxysporum, F. solani, Fusicoccum amygdali, } \\
\text { Monilinia fructicola, Pythium aphanidermatum, } \\
\text { Pythium sp., R. solani, Sclerotinia homoeocarpa, } \\
\text { S. minor, Sphaerotheca fusca, Thielaviopsis } \\
\text { basicola, Tilletia caries, Uncinula necator, } \\
\text { Xanthomonas axonopodis pv. vesicatoria }\end{array}$ & $\begin{array}{l}\text { Apple, cotton, cyclamen, dry } \\
\text { bean, bermudagrass, } \\
\text { geranium, gladiolus, grape, } \\
\text { pansy, peach, peanut, } \\
\text { pepper, potato, snap bean, } \\
\text { soybean, squash, tomato, } \\
\text { wheat }\end{array}$ \\
\hline Beauveria bassiana & 3 & $\ldots$ & R. solani & Cotton, dry bean, soybean \\
\hline Burkholderia cepacia & 13 & Deny & F. oxysporum, F. solani, R. solani & $\begin{array}{l}\text { Cyclamen, gladiolus, dry } \\
\text { bean, potato }\end{array}$ \\
\hline Clonostachys rosea & 1 & $63-28$ & Pythium sp. & Cucumber \\
\hline Comamonas acidovorans & 4 & $\mathrm{C} 4712$ & F. solani, R. solani & Cotton \\
\hline Coniothyrium minitans & 5 & Contans WG & $\begin{array}{l}\text { Cylindrocladium parasiticum, } S . \text { minor, } \\
\text { S. sclerotiorum, Sclerotium rolfsii }\end{array}$ & Peanut, soybean \\
\hline Fusarium oxysporum & 5 & $\begin{array}{l}\text { CS-20NPF, CWB318, } \\
\text { Fo47NPF }\end{array}$ & $F$. oxysporum, $R$. solani & $\begin{array}{l}\text { Asparagus, cyclamen, } \\
\text { gladiolus }\end{array}$ \\
\hline Gliocladium catenulatum & 3 & Primastop & F. solani, T. basicola & Dry bean, pansy \\
\hline Gliocladium virens & 10 & SoilGard & $F$. oxysporum, $R$. solani & Gladiolus, potato \\
\hline Paenibacillus macerans & 3 & GB49, OSU142/3 & R. solani, $X$. axonopodis pv. vesicatoria & Dry bean, pepper \\
\hline Pantoea agglomerans & 2 & C91, E325 & E. amylovora & Apple, pear \\
\hline Pseudomonas flourescens & 8 & $\begin{array}{l}\text { BL915, BlightBan A506, } \\
\text { C7, Dagger, 89B61 }\end{array}$ & $\begin{array}{l}\text { A. solani, E. amylovora, } F \text {. oxysporum, Oidium sp., } \\
\text { Pythium } \mathrm{sp} ., R \text {. solani, X. axonopodis pv. } \\
\text { vesicatoria }\end{array}$ & $\begin{array}{l}\text { Apple, cucumber, cyclamen, } \\
\text { daisy, dry bean, pear, } \\
\text { tomato }\end{array}$ \\
\hline Pseudomonas mendocina & 1 & $3027 \mathrm{C}$ & G. graminis var. trtici & Wheat \\
\hline Pseudomonas putida & 1 & SB40 & G. graminis var. trtici & Wheat \\
\hline Streptomyces griseoviridis & 5 & Mycostop G & F. oxysporum, $F$. solani, $T$. basicola & Dry bean, gladiolus, pansy \\
\hline Streptomyces lydicus & 4 & Actinovate & F. oxysporum, Pythium sp. & $\begin{array}{l}\text { Cyclamen, geranium, } \\
\text { gladiolus }\end{array}$ \\
\hline Stenotrophomonas maltophilia & 4 & $\mathrm{C} 3$ & R. solani, Uromyces appendiculatus & $\begin{array}{l}\text { Dry bean, ryegrass, tall } \\
\text { fescue }\end{array}$ \\
\hline Trichoderma harzianum & 19 & $\begin{array}{l}\text { PlantShield, RootShield, } \\
\text { T-22, T-22 Planter Box }\end{array}$ & $\begin{array}{l}\text { Botrytis cinerea, Colletotrichum acutatum, } \\
\text { F. oxysporum, F. solani, } P \text {. aphanidermatum, } \\
\text { Pythium sp., } R \text {. solani, } T \text {. caries }\end{array}$ & $\begin{array}{l}\text { Cotton, cyclamen, dry bean, } \\
\text { geranium, gladiolus, potato, } \\
\text { raspberry, soybean, } \\
\text { strawberry, wheat }\end{array}$ \\
\hline
\end{tabular}




\section{META-ANALYSIS}

Effect size estimates. The first step in the analysis was the calculation of a common metric ("effect size") for the effectiveness of disease suppression that could be applied to all 149 entries. We used the standardized group mean difference, commonly referred to as Cohen's $d$, which is among the most commonly used and intuitively appealing in meta-analysis (25). For each entry, $d$ was calculated as $\bar{X}_{C}-\bar{X}_{T} / \sigma_{\text {pooled }}$, where $\bar{X}_{T}$ and $\bar{X}_{C}$ are the disease intensity means of the treated and control groups, respectively, and $\sigma_{\text {pooled }}$ is the pooled population standard deviation, calculated from $s_{\text {pooled }}(39)$. Thus, $d$ is the difference in standard deviation units between the biocontrol treatment and its corresponding untreated control. Values of $d>0.2,0.5,0.8$, and 1.0 are considered to represent small, medium, large, and very large effects, respectively $(8,15)$. The variance of $d$ is given by

$$
\sigma^{2}(d)=\frac{n_{T}+n_{C}}{n_{T} n_{C}}+\frac{d^{2}}{2\left(n_{T}+n_{C}\right)}
$$

where $n_{T}$ and $n_{C}$ are the numbers of replicates for the treated and control groups, respectively.

In meta-analysis, each effect size $d_{i}$ (where $i=1$ to $k$ denotes the number of a given entry) is weighted by its corresponding variance, $\sigma^{2}\left(d_{i}\right)$, whereby the weight, $w_{i}$, assigned to each effect size estimate is inversely proportional to its variance,

$$
w_{i}=\frac{1 / \sigma^{2}\left(d_{i}\right)}{\sum_{i=1}^{k}\left[1 / \sigma^{2}\left(d_{i}\right)\right]}
$$

The combined estimate of the effect size across all studies, $d_{+}$, was calculated as

$$
d_{+}=\sum_{i=1}^{k} w_{i} d_{i}
$$

and its variance,

$$
\sigma^{2}\left(d_{+}\right)=\frac{1}{\sum_{i=1}^{k}\left[1 / \sigma^{2}\left(d_{i}\right)\right]}
$$

was used to compute a $95 \%$ confidence interval around $d_{+}$. The total heterogeneity $Q_{T}$ across all $k$ entries is given by

$$
Q_{T}=\sum_{i=1}^{k} w_{i}\left(d_{i}-d_{+}\right)^{2}
$$

$(21,34)$; a value of $Q_{T}$ greater than the theoretical $\chi^{2}$ value (with $k-1$ degrees of freedom) indicates that the variance is greater than expected due to sampling error, warranting a test for moderator variables.

Moderator variables. Several dichotomous or ordinal moderator variables describing biological and application-oriented factors were defined and used to group entries into specific classes (Table 2). Entries were grouped broadly based on whether the corresponding study was carried out in the greenhouse or in the field and whether soilborne or aerial diseases were targeted. Depending on the type of production system, crops were classified as either annual or perennial. A disease pressure variable was defined based on the disease intensity of the untreated control; the corresponding classes were low $(<35 \%$ incidence or severity in the untreated control), moderate ( 35 to $55 \%$ ), and high (>55\%). In cases where disease intensity was reported as an index or on an arbitrary scale, disease pressure was computed by dividing values for the untreated control by the maximum value of the scale to obtain a percentage.

Entries were further classified based on whether they used fungal or bacterial biocontrol agents and were targeted against fungal or bacterial pathogens. In addition, groups were established based on life history traits of pathogen and biological control agent (i.e., whether these organisms were $r$-selected, $K$ selected, or intermediate). In general, $r$-selected species have shorter generation times and produce larger numbers of shorterlived offspring than $K$-selected species (1). For example, in our data set, Pseudomonas fluorescens and Uncinula necator were considered $r$-selected, Fusarium oxysporum and Rhizoctonia solani $K$-selected, and Bacillus subtilis and Gibberella zeae were intermediate biocontrol agents and pathogens, respectively. Inasmuch as possible, we further attempted to distinguish classes based on antagonist-pathogen interactions (e.g., whether a patho-

TABLE 2. Statistics for the effects of moderator variables on the effect size of disease suppression by biological control based on a meta-analysis of reports published in Biological \& Cultural Tests between 2000 and 2005

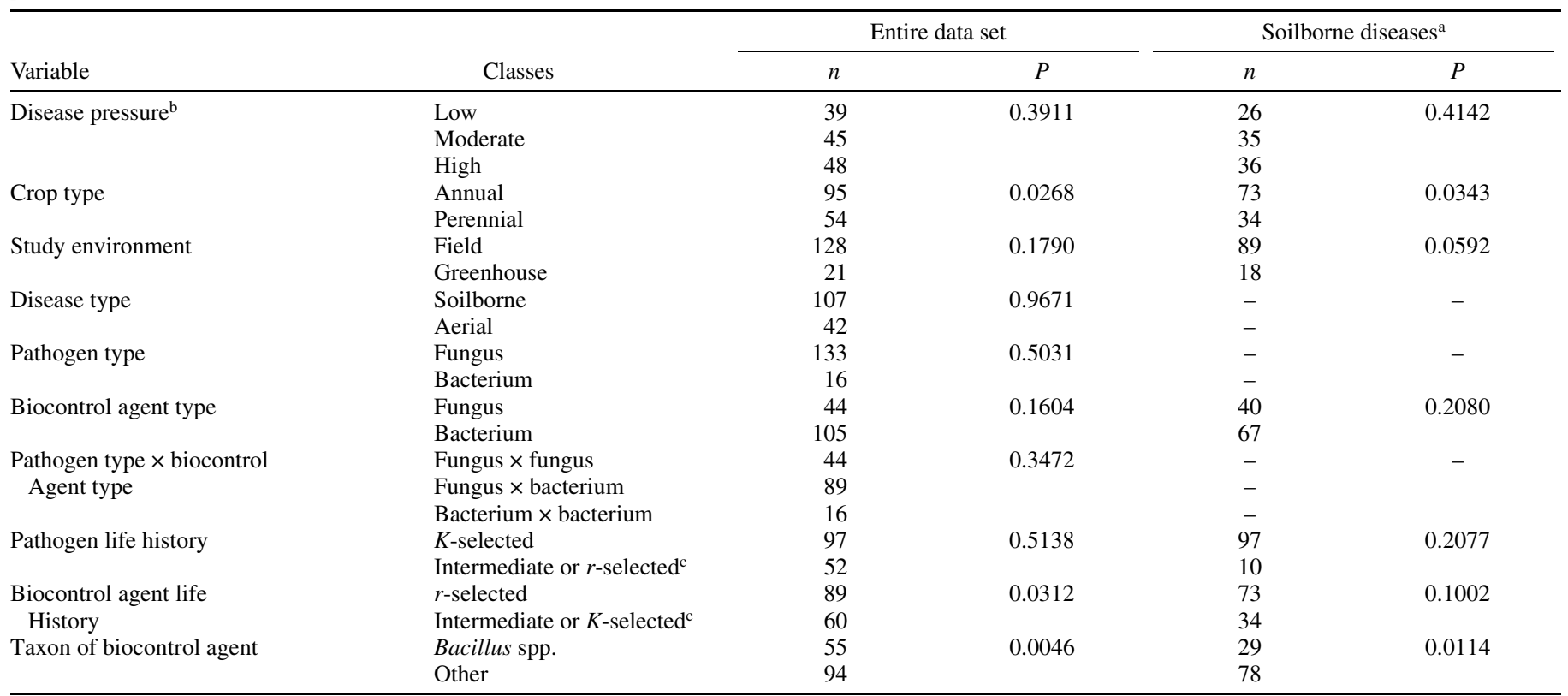

${ }^{a}$ The lower number of entries for soilborne diseases resulted in classes in which the numbers of data points were too low or unbalanced for some moderator variables; no analyses were carried out in these cases.

${ }^{b}$ For each entry, disease pressure classes were defined as low, medium, or high based on disease incidence or severity values in the untreated control of $<35 \%$, 35 to $55 \%$, and $>55 \%$, respectively.

${ }^{\mathrm{c}}$ Classes were grouped together in the analysis to obtain larger and more balanced numbers of entries. 
genic fungus was targeted by an antagonist fungus or bacterium or vice versa); however, not all of these groups could be included based on small or unbalanced numbers of entries per group (Table 2).

A total of 55 of the 149 entries in the data set used Bacillus spp. as biocontrol agents (Table 1). This allowed us to define another moderator variable based on whether Bacillus spp. or other bacterial or fungal species were used as antagonists.

Where possible, the above groupings were defined for the entire data set (i.e., all 149 entries) and separately for entries involving soilborne diseases (107 entries); separate groups were not established when the numbers of entries per group were too low or unbalanced. Because of the relatively low number of entries for aerial diseases $(n=42)$, only one analysis was carried out using this subset of data to determine the effect of number of spray applications of the biocontrol agent ( 1 or 2,3 to 8 , or $>8$ sprays) on $d$.

Analysis of moderator variables. Data were analyzed using meta-analytic methods analogous to one-way analysis of variance to determine whether effect sizes were affected by the moderator variables defined above. For each moderator variable, the SAS macros within, wavgeff, and fixconst (45) were applied to obtain a weighted mean $d$ value for each category (with associated $95 \%$ confidence intervals). Two categories of a moderator variable were considered significantly different from one another if the 95\% confidence interval around the difference of their $d$ values did not include zero (16).

\section{HOW EFFECTIVE IS BIOLOGICAL DISEASE SUPPRESSION?}

The extent of disease suppression by biological control varied widely among entries, with $d$ ranging from -1.15 (i.e., disease strongly enhanced by application of the biocontrol agent) to 4.83 (strong disease suppression by the antagonist) (Fig. 1). Of the 149 entries in the data set, $42 \%$ had a large magnitude of disease suppression $(d>0.8)$ while $26 \%$ of all entries had $d$ values $\leq 0$. This wide range reflects the contrasting opinions in the literature regarding the usefulness of biological control in controlling plant disease $(9,18,27,30,35,37)$. The combined mean effect size across studies $\left(d_{+}\right)$was 0.62 , indicating that biocontrol was moderately effective on average. The $95 \%$ confidence interval of $d_{+}$ranged

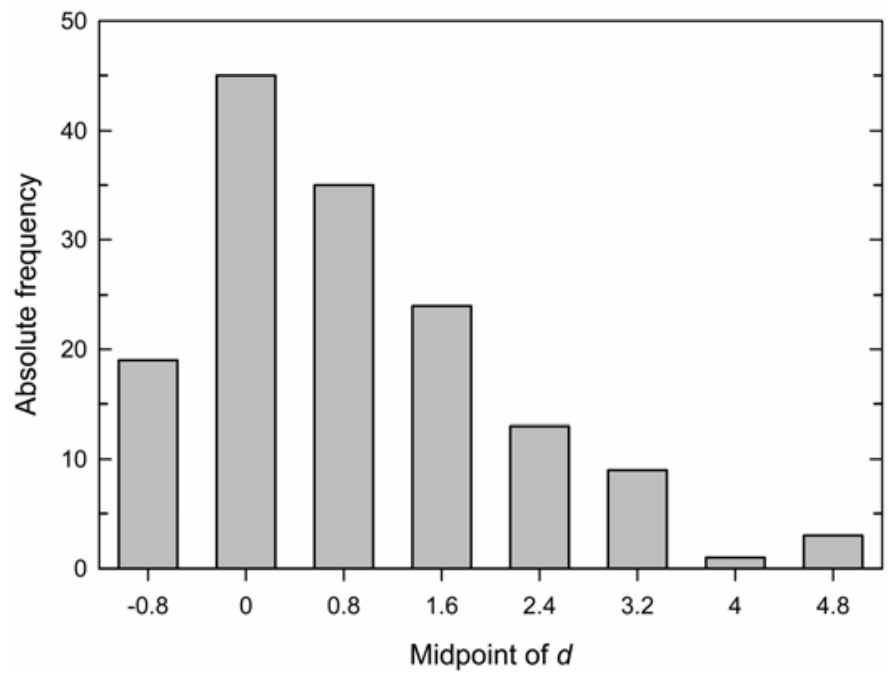

Fig. 1. Frequency distribution of the effect size, $d$, of disease suppression by biological control based on a meta-analysis of reports published in Biological \& Cultural Tests between 2000 and $2005(n=149) ; d$ is the difference in standard deviation units between the biocontrol treatment and its corresponding untreated control, with values of $>0.2,0.5,0.8$, and 1.0 representing small, medium, large, and very large effects, respectively. from 0.51 to 0.73 , showing that the overall effect size was significantly $>0$.

The null hypothesis of homogeneity across studies was rejected $\left(Q_{T}=181.7, \mathrm{df}=148, P<0.05\right)$, indicating that variability in $d$ was greater than would be expected due to random sampling error. Thus, a fixed-effect meta-analysis was performed to determine the effect of moderator variables on disease suppression.

\section{WHAT ARE THE FACTORS AFFECTING BIOLOGICAL DISEASE SUPPRESSION?}

Host and environmental factors. There were no significant $(P>0.05)$ differences in effect sizes among entries from studies carried out in conditions of low, moderate, or high disease pressure (Table 2). However, biocontrol was significantly more effective on annual than on perennials crops, regardless of whether the analysis was carried out for all entries or for those involving only soilborne diseases (Fig. 2). The significantly lower magnitude of disease suppression in perennial crops may be due to the larger number of potential pathogen inoculum sources (such as cankers, leaf scars, or buds harboring pathogen populations) in perennial pathosytems, which give rise to polyetic epidemics that generally are more difficult to control. Furthermore, in the absence of crop rotation in perennial crops, pathogen populations may build up and the resident microbial community may be more resilient, hindering colonization by externally applied biocontrol agents. The fact that $d$ was, on average, $\approx 40 \%$ lower on perennial crops than on annual crops highlights the need for further research on the dynamics of pathogen populations, the resident microflora, and the introduced biocontrol agent on such crops and how their interactions affect the success or failure of biological control.

In a review of biological control of plant diseases in greenhouse systems, Paulitz and Bélanger (35) pointed out that the greenhouse environment presents a unique situation that enables disease managers to optimize the effectiveness of biological control agents through manipulation of environmental conditions. For example, biocontrol agents against powdery mildews are more efficient when relative humidity can be maintained $>80 \%$, a condition that is easily monitored and adjusted in the greenhouse (4).

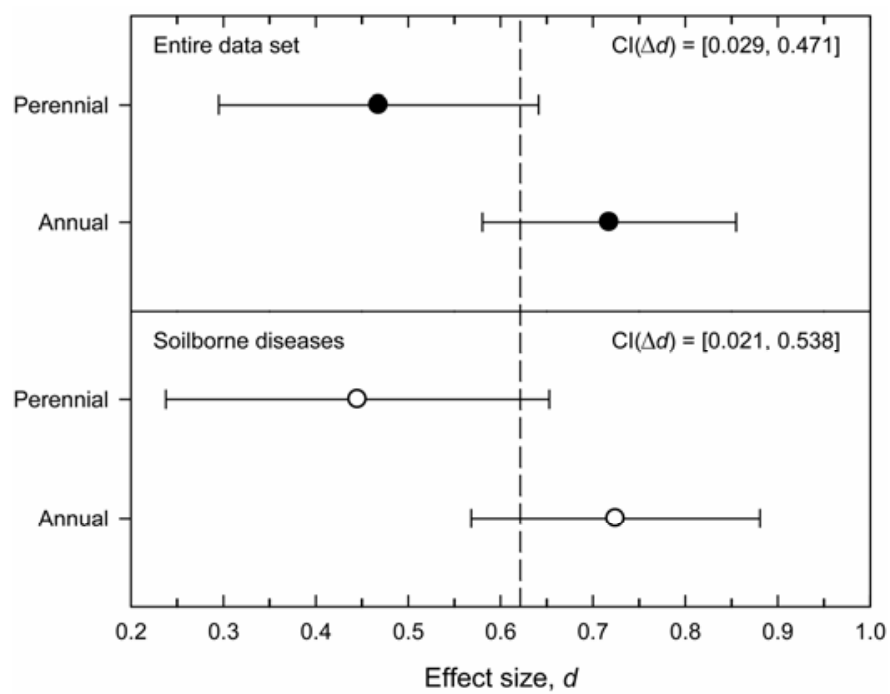

Fig. 2. Effect of crop type (annual versus perennial) on the effect size, $d$, of disease suppression by biological control based on a meta-analysis of reports published in Biological \& Cultural Tests between 2000 and $2005(n=149)$; $d$ is the difference in standard deviation units between the biocontrol treatment and its corresponding untreated control, with values of $>0.2,0.5,0.8$, and 1.0 representing small, medium, large, and very large effects, respectively. Error bars indicate the $95 \%$ confidence interval, while the dotted vertical line shows the overall weighted mean across all entries. $\mathrm{CI}(\Delta d)$ is the $95 \%$ confidence interval around the difference in effect sizes between the two crop types. 
Thus, it is reasonable to expect greater disease suppression in greenhouse than in the field applications of biocontrol agents. However, our analysis showed no significant difference in mean effect sizes between entries in which biological agents were applied in these two environments (Table 2). We hypothesize that this may have been due to the fact that the studies carried out in the greenhouse generally included multiple treatments, most of which involved different biocontrol agents (as opposed to different application schedules or rates, for example). Given the different environmental preferences of the different antagonists, it would have been impossible to adjust the greenhouse environment so as to optimize performance of all of the included agents simultaneously. The dilemma faced by greenhouse managers when attempting to adjust environmental conditions to enhance biocontrol without at the same time encouraging disease development has been discussed previously by Jewett and Jarvis (24).

Pathogen and antagonist-related factors. Effect sizes were not significantly different between entries involving fungal versus bacterial biocontrol agents or between those targeting fungal versus bacterial pathogens or soilborne versus aerial diseases (Table 2). Similarly, there were no significant differences when fungal pathogens were targeted with bacterial biocontrol agents, fungal pathogens were targeted with fungal biocontrol agents, or bacterial pathogens were targeted with bacterial biocontrol agents. (There were no entries in the data set for bacterial pathogens targeted with fungal biocontrol agents.) Mean effect sizes also did not differ between entries in which pathogens were $K$ selected versus $r$-selected or intermediate along the $r$-to- $K$ continuum. However, entries in which $r$-selected microorganisms were used as biocontrol agents had a greater mean effect size than those in which biological agents were not $r$-selected (Fig. 3), although this effect was not statistically significant when the analysis was restricted to entries involving only soilborne diseases (Table 2).

For effective disease suppression, most biological control agents need to build up large population sizes within their respective niches $(30,31,46)$. This may be the reason why treatments with $r$ selected biological control agents had significantly greater effect sizes than those in which biological control agents that are not $r$ selected were applied. Although $r$-selected microorganisms ex-

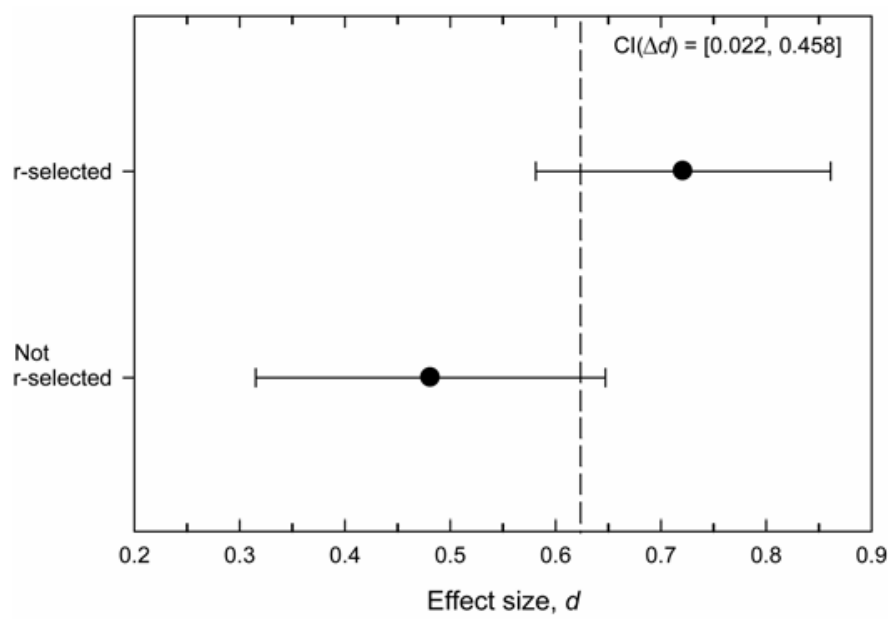

Fig. 3. Effect of biocontrol agent life history ( $r$-selected versus $K$-selected or intermediate) on the effect size, $d$, of disease suppression by biological control based on a meta-analysis of reports published in Biological \& Cultural Tests between 2000 and $2005(n=149) ; d$ is the difference in standard deviation units between the biocontrol treatment and its corresponding untreated control, with values of $>0.2,0.5,0.8$, and 1.0 representing small, medium, large, and very large effects, respectively. Error bars indicate the $95 \%$ confidence interval, while the dotted vertical line shows the overall weighted mean across all entries. $\mathrm{CI}(\Delta d)$ is the $95 \%$ confidence interval around the difference in effect sizes between the two life history categories. hibit larger fluctuations in population size (1), in favorable environmental conditions they reproduce prolifically, reaching larger numbers within a relatively short time. As such, $r$-selected biological agents have been described as the equivalents to protectant fungicides, being in place before infection starts (7). This characteristic is highly compatible with the general strategy of inundative biocontrol used for plant disease control, where the antagonist is applied at an instantly high population size with the intent to preempt the pathogen.

A total of 55 of the 149 entries in the data set used Bacillus spp. as biocontrol agents (Table 1). Interestingly, the mean effect size for these entries was significantly lower compared with entries that applied other biocontrol organisms, regardless of whether the analysis was carried out for all studies or separately for those involving soilborne diseases. In both cases, the mean effect size for the entries utilizing Bacillus spp. was $>40 \%$ lower (Fig. 4). This finding is at odds with the fact that the most thoroughly studied biological control bacteria have been species in the genus Bacillus (32). Furthermore, considerable efforts have been devoted to integrating Bacillus spp.-based biological control agents into practical disease management systems $(6,23)$. Bacillus spp. have many advantages as biocontrol agents, including their ability to produce broad-spectrum antibiotics (28) as well as endospores, which facilitate commercial formulation and enhance shelf life (41). However, given the wide availability of commercial Bacillus-based biocontrol products (13), it is tempting to include these products in indiscriminate efficacy screens without due consideration of whether the biocontrol agent is a good match for the pathogen or host niche in question. For example, the epiphytic fitness of Bacillus spp. such as B. subtilis on aboveground plant surfaces generally is low (40), yet close to $20 \%$ of the entries in the data set that applied Bacillus spp. did so against aerial diseases. Cook (9) suggested that inconsistencies in the efficacy of biological control may be due to the use of a single strain of the agent everywhere, and a similar indiscriminate application of a few widely used Bacillus strains may be reflected in our data set. Indeed, 21 of the 55 Bacillus entries in the data set utilized the QRD and QST strains of B. subtilis commercially

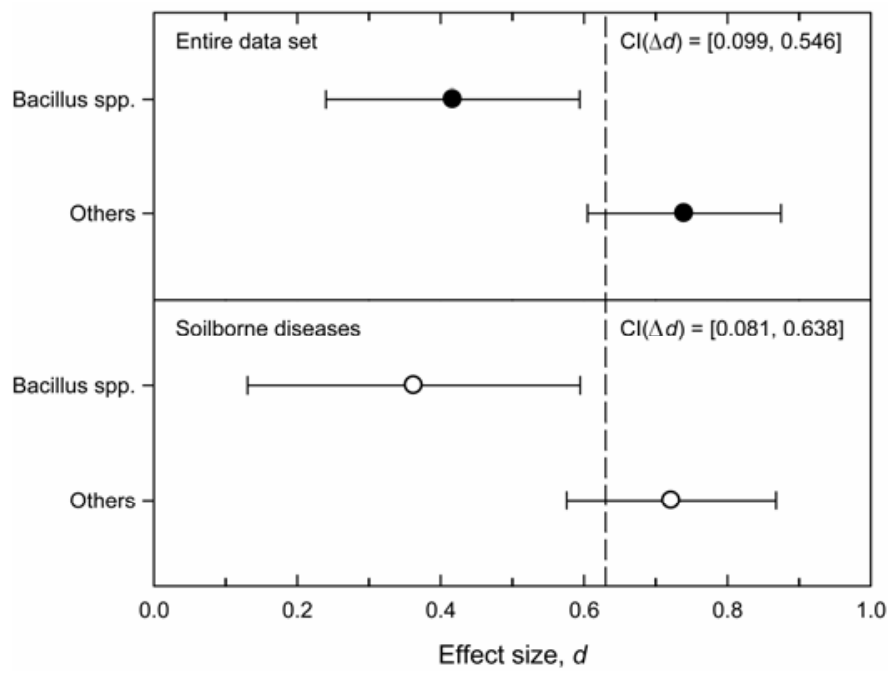

Fig. 4. Effect of biocontrol taxon (Bacillus spp. versus all other bacterial and fungal species) on the effect size, $d$, of disease suppression by biological control based on a meta-analysis of reports published in Biological \& Cultural Tests between 2000 and $2005(n=149) ; d$ is the difference in standard deviation units between the biocontrol treatment and its corresponding untreated control, with values of $>0.2,0.5,0.8$, and 1.0 representing small, medium, large, and very large effects, respectively. Error bars indicate the $95 \%$ confidence interval, while the dotted vertical line shows the overall weighted mean across all entries. $\mathrm{CI}(\Delta d)$ is the $95 \%$ confidence interval around the difference in effect sizes between the two taxonomic groups. 
formulated as Serenade biofungicide. When these 21 entries were omitted from the analysis, the difference in efficacy between Bacillus-based biocontrol agents and other antagonist species was no longer statistically significant for the full data set $(P=0.0724$, $n=128$ ); however, when the analysis was restricted to soilborne diseases, the Bacillus-based entries still were significantly less effective $(P=0.0372, n=103)$.

Number of applications against aerial diseases. Because of the relatively low number of entries involving aerial diseases $(n=$ 42 ), only one analysis was carried out using this subset of data to determine the effect of number of spray applications of the biocontrol agent. In this analysis, entries with few applications (one or two sprays) of the biological control agents had a significantly $(P=0.0002)$ greater mean effect size than those in which a large number of applications (more than eight sprays) was made (Fig. 5). Theoretically, if a biological agent is inherently effective in suppressing a pathogen on a given host, a limited number of applications should be sufficient to achieve the intended results. Therefore, it is reasonable to conclude that, in instances where the biocontrol agent is deemed less effective (e.g., in cases where season-long control in a niche unfavorable for the antagonist is needed), more applications will be made in an effort to compensate for the anticipated low efficacy of biocontrol agents. As such, our result may indicate that investigators often attempt unsuccessfully to compensate for anticipated poor performance in antagonist-disease combinations by making more applications.

Factors not included in the analysis. We acknowledge that there are additional factors potentially affecting the effectiveness of biological control that were not considered in our analyses. Foremost among these is the mechanism of action of the biocontrol agent (i.e., whether the antagonist operates via competition, antibiosis, hyperparasitism, or induced host resistance). Assigning a single mechanism of action is highly problematic because most antagonists are believed to suppress disease via multiple mechanisms acting simultaneously $(11,19)$. For example, although mycoparasitism and antibiosis $(3,49)$ traditionally have been viewed as the most important mechanisms involved in biological control by Trichoderma harzianum, it is now recognized

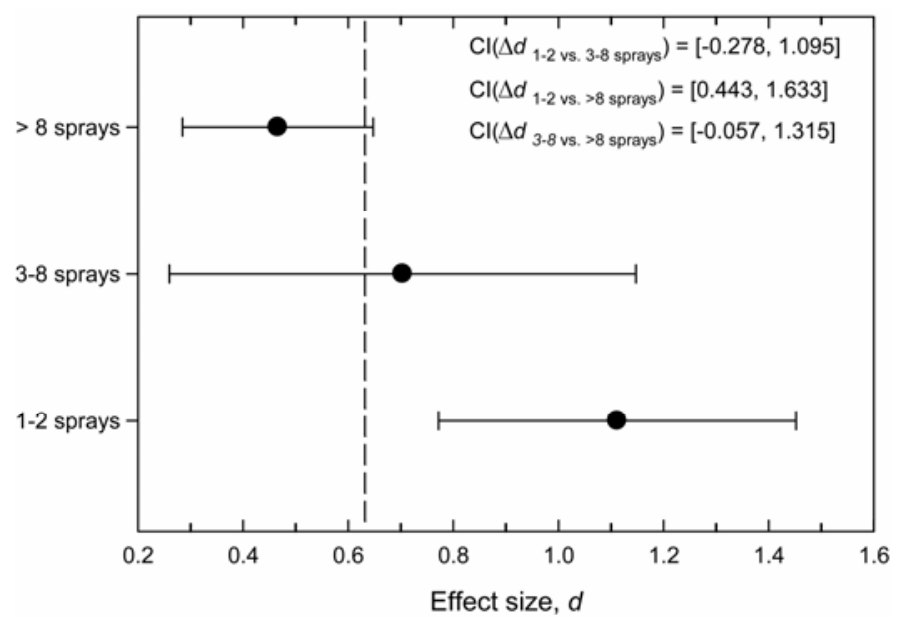

Fig. 5. Effect of number of applications on the effect size, $d$, of disease suppression by biological control based on a meta-analysis of reports published in Biological \& Cultural Tests between 2000 and 2005. Analysis restricted to entries involving aerial diseases $(n=42) ; d$ is the difference in standard deviation units between the biocontrol treatment and its corresponding untreated control, with values of $>0.2,0.5,0.8$, and 1.0 representing small, medium, large, and very large effects, respectively. Error bars indicate the 95\% confidence interval, while the dotted vertical line shows the overall weighted mean across all entries. $\mathrm{CI}(\Delta d)$ is the $95 \%$ confidence interval around the pairwise differences in effect sizes between the three application frequency categories. that induced host resistance plays a major role in some pathosystems $(5,12,20,22,47)$ and that different mechanisms operating at the same time can act additively or synergistically $(3,14,18,48)$. In the absence of more precise data on the relative importance of different mechanisms of action in different host-pathogenantagonist systems, we considered it imprudent to include this factor in our analysis.

As stated above, studies that evaluated combinations of multiple biological control agents or of biological agents applied jointly with cultural practices or chemical products were not included in our analyses because it would have been impossible to calculate the contribution of each individual antagonist. Thus, we were not able to test whether and to what extent combined applications of antagonists are more effective than single applications, as has been suggested in numerous individual studies $(11,14,36)$. In a recent meta-analysis of factors affecting the success of biological control of arthropod pests (43), multi-species releases of biocontrol agents consistently were more effective than singlespecies releases. Future research using meta-analytical techniques should determine whether a similar general conclusion applies to plant pathogens as well.

\section{CONCLUSIONS}

This is the first meta-analysis to provide quantitative information on selected factors impacting the effectiveness of biological control in suppressing plant disease for a wide range of antagonist-disease systems. The analysis identified several general factors that consistently affected the performance of biological control of plant disease across a wide range of environments and host-pathogen-antagonist combinations. Some of the findings confirmed theoretical expectations (e.g., the greater effect size associated with $r$-selected antagonists), whereas others appear to be at odds with conventionally held wisdom (e.g., similar effect sizes in studies carried out in the greenhouse versus the field). Future research, perhaps involving a larger data base, is needed to test some aspects that were not included in the present analysis. A larger data base also would allow one to test more specific hypotheses related to specific groups of biocontrol agents or even specific disease-antagonist combinations, based on the increased recognition that antagonist strains, formulations, and application methods may need to be optimized for each disease on a particular crop at a particular site $(9,42)$. Nonetheless, we believe there must be some universal principles that apply to a wide range of antagonist-disease-crop combinations, and we hope that this research has provided a step toward their quantitative analysis.

\section{ACKNOWLEDGMENTS}

We thank M. Wang, University of Central Florida, for suggestions relative to the use of some meta-analytical tools.

\section{LITERATURE CITED}

1. Andrews, J. H., and Harris, R. F. 1986. $r$ - and $K$-selection and microbial ecology. Adv. Microbiol. Ecol. 9:99-147.

2. Andrews, J. H., and Harris, R. F. 2000. The ecology and biogeography of microorganisms on plant surfaces. Annu. Rev. Phytopathol. 38:145-180.

3. Bélanger, R. R. 1995. Chronological events associated with the antagonistic properties of Trichoderma harzianum against Botrytis cinerea: Indirect evidence for sequential role of antibiosis and parasitism. Biocontrol Sci. Technol. 5:41-54.

4. Bélanger, R. R., and Benyagoub, M. 1997. Challenges and prospects for integrated control of powdery mildews in the greenhouse. Can. J. Plant Pathol. 19:310-314.

5. Benitez, T., Rincón, A. M., Limón, M. C., and Codón, A. C. 2004. Mecanismos de biocontrol de cepas de Trichoderma. Int. Microbiol. 7:249-260.

6. Brannen, P. M., and Kenney, D. S. 1997. Kodiak-A successful biological control product for suppression of soil-borne plant pathogens of cotton. J. Ind. Microbiol. Biotechnol. 19:169-171. 
7. Campbell, R. 1989. Biological Control of Microbial Plant Pathogens. Cambridge University Press, Cambridge.

8. Cohen, J. 1988. Statistical Power Analysis for the Behavioral Sciences, 2nd ed. Lawrence Erlbaum, Hillsdale, NJ.

9. Cook, R. J. 1993. Making greater use of introduced microorganisms for biological control of plant pathogens. Annu. Rev. Phytopathol. 31:53-80.

10. Cook, R. J. 2000. Advances in plant health management in the twentieth century. Annu. Rev. Phytopathol. 38:95-116.

11. de Boer, M., Bom, P., Kindt, F., Keurentjes, J. B., van der Sluis, I., van Loon, L. C., and Bakker, P. A. H. M. 2003. Control of Fusarium wilt of radish by combining Pseudomonas putida strains that have different disease-suppressive mechanisms. Phytopathology 93:626-632.

12. de Meyer, G., Bigirimana, J., Elad, Y., and Höfte, M. 1998. Induced systemic resistance in Trichoderma harzianum T39 biocontrol of Botrytis cinerea. Eur. J. Plant Pathol. 104:279-286.

13. Fravel, D. R. 2005. Commercialization and implementation of biocontrol. Annu. Rev. Phytopathol. 43:337-359.

14. Guetsky, R., Shtienberg, D., Elad, Y., Fischer, E., and Dinoor, A. 2002. Improving biological control by combining biocontrol agents each with several mechanisms of disease suppression. Phytopathology 92:976-985.

15. Gurevitch, J., and Hedges, L. V. 1993. Meta-analysis: Combining the results of independent experiments. Pages 378-398 in: Design and Analysis of Ecological Experiments. S. M. Scheiner and J. Gurevitch, eds. Chapman \& Hall, New York.

16. Gurevitch, J., and Hedges, L. V. 1999. Statistical issues in ecological meta-analyses. Ecology 80:1142-1149.

17. Handelsman, J., and Stabb, E. V. 1996. Biocontrol of soilborne plant pathogens. Plant Cell 8:1855-1869.

18. Harman, G. E. 2000. Myths and dogmas of biocontrol: Changes in perceptions derived from research on Trichoderma harzianum T-22. Plant Dis. 84:377-393.

19. Harman, G. E. 2006. Overview of mechanisms and uses of Trichoderma spp. Phytopathology 96:190-194.

20. Harman, G. E., Petzoldt, R., Comis, A., and Chen, J. 2004. Interactions between Trichoderma harzianum strain T22 and maize inbred line Mo17 and effects of these interactions on diseases caused by Pythium ultimum and Colletotrichum graminicola. Phytopathology 94:147-153.

21. Hedges, L. V., and Olkin, I. 1985. Statistical Methods for Meta-Analysis. Academic Press, Orlando, FL.

22. Hoitink, H. A. J., Madden, L. V., and Dorrance, A. E. 2006. Systemic resistance induced by Trichoderma spp.: Interactions between the host, the pathogen, the biocontrol agent, and soil organic matter quality. Phytopathology 96:186-189.

23. Jacobsen, B. J., Zidack, N. K., and Larson, B. J. 2004. The role of Bacillus-based biological control agents in integrated pest management systems: Plant diseases. Phytopathology 94:1272-1275.

24. Jewett, T. J., and Jarvis, W. R. 2001. Management of the greenhouse microclimate in relation to disease control: A review. Agronomie 21:351366.

25. Kelley, K. 2005. The effects of nonnormal distributions on confidence intervals around the standardized mean difference: Bootstrap and parametric confidence intervals. Educ. Psychol. Meas. 65:51-69.

26. Kinkel, L. L. 1997. Microbial population dynamics on leaves. Annu. Rev. Phytopathol. 35:327-347.

27. Kishore, G. K., Pande, S., and Podile, A. R. 2005. Biological control of collar rot disease with broad-spectrum antifungal bacteria associated with groundnut. Can. J. Microbiol. 51:123-132.

28. Leifert, C., Li, H., Chidburee, S., Hampson, S., Workman, S., Sigee, D., Epton, H. A., and Harbour, A. 1995. Antibiotic production and biocontrol activity by Bacillus subtilis CL27 and Bacillus pumilus CL45. J. Appl. Bacteriol. 78:97-108
29. Loper, J. E., and Stockwell, V. O. 2000. Current status of biological control of plant diseases. Pages 240-256 in: Emerging Technologies for Integrated Pest Management. G. C. Kennedy and T. B. Sutton, eds. The American Phytopathological Society, St. Paul, MN.

30. Mathre, D. E., Cook, R. J., and Callan, N. W. 1999. From discovery to use: Traversing the world of commercializing biocontrol agents for plant disease control. Plant Dis. 83:972-983.

31. McGuire, R. G. 2000. Population dynamics of postharvest decay antagonists growing epiphytically and within wounds on grapefruit. Phytopathology 90:1217-1223.

32. McSpadden-Gardener, B. B. 2004. Ecology of Bacillus and Paenibacillus spp. in agricultural systems. Phytopathology 94:1252-1258.

33. Meneley, J. C. 2000. Challenges in the commercialization of biological control technologies for IPM. Pages 289-304 in: Emerging Technologies for Integrated Pest Management. G. C. Kennedy and T. B. Sutton, eds. The American Phytopathological Society, St. Paul, MN.

34. Olkin, I., and Shaw, D. V. 1995. Meta-analysis and its applications in horticultural science. HortScience 30:1343-1348.

35. Paulitz, T. C., and Bélanger, R. R. 2001. Biological control in greenhouse systems. Annu. Rev. Phytopathol. 39:103-133.

36. Raupach, G. S., and Kloepper, J. W. 1998. Mixtures of plant growthpromoting rhizobacteria enhance biological control of multiple cucumber pathogens. Phytopathology 88:1158-1164.

37. Roberts, D. P., and Lohrke, S. M. 2003. United States Department of Agriculture-Agricultural Research Service research programs in biological control of plant diseases. Pest Manage. Sci. 59:654-664.

38. Rosenthal, R. 1979. The "file-drawer problem" and tolerance for null results. Psychol. Bull. 86:638-641.

39. Rosnow, R. L., and Rosenthal, R. 1996. Computing contrasts, effect sizes, and counternulls on other people's published data: General procedures for research consumers. Psychol. Methods 1:331-340.

40. Scherm, H., Ngugi, H. K., Savelle, A. T., and Edwards, J. R. 2004. Biological control of infection of blueberry flowers caused by Monilinia vaccinii-corymbosi. Biol. Control 29:199-206.

41. Schisler, D. A., Slininger, P. J., Behle, R. W., and Jackson, M. A. 2004. Formulation of Bacillus spp. for biological control of plant diseases. Phytopathology 94:1267-1271.

42. Spadaro, D., and Gullino, M. L. 2005. Improving the efficacy of biocontrol agents against soilborne pathogens. Crop Prot. 24:601-613.

43. Stiling, P., and Cornelissen, T. 2005. What makes a successful biocontrol agent? A meta-analysis of biological control agent performance. Biol. Control 34:236-246

44. Vasudevan, P., Kavitha, S., Priyadarisini, V. B., Babujee, L., and Gnanamanickam, S. S. 2002. Biological control of rice diseases. Pages 387-420 in: Biological Control of Crop Diseases. S. S. Gnanamanickam, ed. Marcel Dekker, New York.

45. Wang, M. C., and Bushman, B. J. 1999. Integrating Results through MetaAnalytic Review Using SAS software. SAS Institute, Cary, NC.

46. Whipps, J. M. 2001. Microbial interactions and biocontrol in the rhizosphere. J. Exp. Bot. 52:487-511.

47. Yedidia, I., Benhamou, N., and Chet, I. 1999. Induction of defense responses in cucumber plants (Cucumis sativus L.) by the biocontrol agent Trichoderma harzianum. Appl. Environ. Microbiol. 65:1061-1070.

48. Yedidia, I., Benhamou, N., Kapulnik, Y., and Chet, I. 2000. Induction and accumulation of PR proteins activity during early stages of root colonization by the mycoparasite Trichoderma harzianum strain T-203. Plant Physiol. Biochem. 38:863-873.

49. Zeilinger, S., Galhaup, C., Payer, K., Woo, S. L., Mach, R. L., Fekete, C., Lorito, M., and Kubicek, C. P. 1999. Chitinase gene expression during mycoparasitism interaction of Trichoderma harzianum with its host. Fungal Genet. Biol. 26:131-140. 